Repair of the Anterior Cruciate Ligament With Anterolateral Ligament Augmentation.

2. Trân Hoàng Tùng (2018). Nghiên cứu ứng dụngphẫu thuật nội soi tái tạo hai bó dây chằng chéo trước sử dung gân bánh chè đồng loại. Luân án tiến sỹ trường Đại học Y Hà Nội.

3. Trân Trung Dũng (2011), Nghiên cứu sử dụng mảnh ghép đồng loại bảo quản lạnh sâu tạo hình dây chẳng chéo trưởc khớp gối qua nội soi, Luận văn tiến sỹ y hoc. Trường Đai hoc $Y$ Hà Nôi.

4. Lê Mạnh Sơn (2015), Nghiên cứu ứng dưng phẫu thuât nội soi tái tao dây chằng chéo trước hai bó bằng gân cơ bán gân và gân cơ thon tự thân. Luận ántiến sỹ, trường Đại học $Y$ Hà Nội.

5. Kristian Nikolaus Schneider et al (2020) Good to Excellent Functional Short-Term Outcome and Low Revision Rates Following Primary Anterior Cruciate Ligament Repair Using Suture Augmentation.

6. Harmen D. Vermeijden et al (2021), Reliable Internal Consistency and Adequate Validity of the Forgotten Joint Score-12 after Primary Anterior Cruciate Ligament Repair.

7. R Kalina et all (2019). InternalBrace $A C L$ Repair- First Experiences and Outcomes.

\title{
ĐÁNH GIÁ KẾT QUẢ PHẪU THUÂTTHAY BÁN PHẦN KHỚP GỐI CÓ HỖ TRỢ CỦA ROBOT TẠI BÊ̂NH VIỆN BACH MAI
}

\section{TÓM TẮT}

Mục tiêu: Mô tả đặ̆c điểm dịch tễ, chẩn đoán hình ảnh và kết quả phẫu thuật thay bán phân khớp gối có hỗ trợ của Robot. Phương pháp nghiên cứu: Nghiên cứu hồi cứu và thông kê mộ tả 32 bệnh nhân thoái hóa khớp gối được điêuu trị phẫu thuật thay khớp gối bán phần tại bệnh viện Bạch Mai từ tháng 3/2017 đến tháng 4/2019. Kết quả: Tỷ lệ nữ/nam là $5,4 / 1$, độ tuổi trung bình là 65 tuổi. $18,8 \%$ bệnh nhân thoái hóa khớp gối độ II và $81,2 \%$ bệnh nhân thoái hóa khớp gối độ III theo phân độ Kellgren và Lawrence. Sau phẫu thuật điểm Lysholm cải thiện có ý nghĩa thống kê giữa các nhóm tuổi, mức đô thoái hóa khớp gối và phân loại $B M I$ với $p \leq 0,05$. Kết luận: Thoái hóa khớp gối ngày càng phổ biến, bên canh thay khớp gối toàn phân thay khớp gối bán phân được phát triển cho các bênh nhân thoái hóa gối 1 khoang, cùng với sư phát triển của khoa học và công nghệ thay khớp gổi bán phần có hố trớ của Robot được phát triển và đat được nhưng kết quả tốt so với thay khớp gối bán phần truyền thống.

Tư khóa: Thay khớp gối bán phân, Robot.

\section{SUMMARY}

\section{ASSESSMENT OF SURGERY RESULTS OF ROBOTIC ASSISTED PARTIAL KNEE} REPLACEMENT AT BACH MAI HOSPITAL

Aims: Describe epidemiological, imaging features and evaluate the surgical results of Robotic assisted partial knee replacement. Patients and methods: Retrospective and descriptive study of 32 patients who were diagnosed with knee osteoarthritis and treated partial knee replacement at Bach Mai hospital from 3/2017 to 4/2019. Results: In 32 patients, the

\footnotetext{
${ }^{1}$ Trường Đại học Y Hà Nội,

${ }^{2}$ Bênh viên Bach Mai

Chịu trách nhiệm chính: Đào Xuân Thành

Email: daoxuanthanh@hmu.edu.vn

Ngày nhận bài: 17.8.2021

Ngày phản biên khoa hoc: 18.10.2021

Ngày duyệt bài: 27.10 .2021
}

Nguyễn Đình Cẩn ${ }^{1}$, Đào Xuân Thành ${ }^{1,2}$

female/male ratio was $5,4 / 1$, the mean age was 65 years. According to Kellgren and Lawrence classification,the rates of patients with grade II and grade III were $18,8 \%$ and $81,2 \%$, respectively. The Lysholm score algorithm significantly improved the age groups, the degree of knee osteoarthritis and BMI. Conclusion: Knee osteoarthritis is becoming more and more common, besides total knee replacement, partial knee replacement has been developed for patients with a single compartment knee osteoarthritis, along with the development of science and technology of joint replacement. Robotassisted partial knee replacement is developed and achieved with good results compared to traditional partial knee replacement.

Keywords: Partial knee replacement, Robot.

\section{I. ĐẶT VẤN ĐỀ}

Thoái hóa khớp gối là bệnh lý ngày càng phổ biến ở Việt Nam, trong đó tỷ lệ bệnh nhân thoái hóa khớp gối tiên phát, thoái hóa khớp sau chấn thương, thấp khớp ngày càng tăng ảnh hưởng đến sinh hoạt của người bệnh. Có nhiều phương pháp điều trị thoái hóa khớp gối như phục hồi chức năng, giảm cân, điều trị nội khoa bằng thuốc, phầu thuật nội soi làm sạch, ghép sụn... Bệnh nhân có chỉ định thay khớp gối khi các phương pháp trên thất bại. Thay khớp gối toàn phần bắt đầu được tiến hành từ nhiêu thập kỷ trước tại Việt Nam và đem lại kết quả tốt. Tuy nhiên trong trường hợp khớp gối chỉ tổn thương một trong ba khoang, các phẫu thuật viên có thể thay thế từng khoang mà không nhất thiết phải thay toàn bộ khớp gối, giảm sang chấn và đem lại sự phục hồi chức năng vận động nhanh chóng hơn cho người bệnh. Mặc dù vậy việc thay một khoang có thể gặp khó khăn về mặt kỹ thuật hơn so với thay toàn bộ khớp gối do phần khớp gối được thay phải phù hợp các phần còn lại của khớp gối cả về kích thước, vị trí... Cùng với sự 
phát triển của khoa học kỹ thuật, thay khớp gối bán phân có hỗ trợ của Robot đã được áp dụng để gia tăng độ chính xác, mang lại sự hồi phục nhanh chóng và kết quả lâu dài cho người bệnh. Vì vậy, chúng tôi tiến hành nghiên cứu này với mục tiêu: Nhận xét một số yếu tố liên quan đên kết quả sớm phẫu thuật thay bán phân khớp gôi có hỗ trơ của Robot.

\section{II. ĐỐI TƯỢNG VÀ PHƯƠNG PHÁP NGHIÊN CỨU}

2.1 Đối tượng nghiên cứu: Gồm 32 bệnh nhân được chẩn đoán thoái hóa khớp gối và được phẫu thuật thay bán phân khớp gối có hỗ trợ của Robot tại khoa CTCH\&CS bệnh viện Bạch Mai từ tháng 3/2017 đến tháng 4/2019.

\section{Tiêu chuẩn lưa chọn}

- Bao gồm tất cả các bệnh nhân được phẫu thuật thay khớp gối bán phần có hỗ trợ của robot tại khoa CTCH\&CS bệnh viện Bạch Mai từ tháng 3/2017 đến tháng 4/2019.

- Có đầy đủ hồ sơ bệnh án, phim chụp Xquang trước và sau mổ.

- Bệnh nhân đồng ý tham gia nghiên cứu.

Tiêu chuẩn loại trữ:Loại khỏi diện nghiên cứu những bệnh nhân không có đây đủ các tiêu chuẩn trên.

\subsection{Phương pháp nghiên cứu:}

Thiết kế nghiên cứu: Nghiên cứu mô tả hồi cứu.

Phương pháp thu thập số liệu: Thu thập thông tin số liệu dựa trên khai thác hồ sơ bệnh án và kết quả khám lại sau mổ.

\subsection{Nội dung nghiên cứu}

- Đặc điểm lâm sàng: tuổi, giới, BMI.

Bảng 2. Điểm Lysholm theo nhóm tuổi

\begin{tabular}{|c|c|c|c|c|}
\hline Tuối & Số BN (N=32) & Trước mố & Sau mố & \multirow{2}{*}{ Giá trị p } \\
\hline$\leq 50$ & 1 & 65 & 96 & \multirow{2}{*}{0,262} \\
\cline { 1 - 4 } $51-60$ & 9 & $60,9 \pm 1,52$ & $92,1 \pm 1,32$ & \\
\hline $61-70$ & 16 & $61,2 \pm 0,7$ & $90 \pm 0,88$ & \\
\hline$>70$ & 6 & $59,5 \pm 0,76$ & $88,8 \pm 0,91$ & \\
\hline
\end{tabular}

Nhận xét: Điểm Lysholm sau mổ ở các nhóm bệnh nhân cao hơn so với trước mổ, tuy nhiên sự thay đổi điểm Lysholmkhông khác biệt giữa các nhóm tuổi $(p=0,262)$.

Bảng 3. Điểm Lysholm theo mức độ thoái hóa khớp gối

\begin{tabular}{|c|c|c|c|c|}
\hline & Số khớp & Điếm Lysholm trước mố & Điếm Lysholm sau mố & Giá trị p \\
\hline Độ II & 6 & $64,8 \pm 0,79$ & $94,2 \pm 1,08$ & 0,000 \\
\hline Độ III & 26 & $60 \pm 0,55$ & $89,7 \pm 0,66$ & 0 \\
\hline
\end{tabular}

Nhận xét: BN trong nghiên cứu của chúng tôi chủ yếu thoái hóa khớp gối độ II, III. Thay đổi điểm Lysholm trước và sau mổ khác biệt có ý nghĩa thống kê giữa các mức độ thoái hóa với p =0,000.

Bảng 4. Điểm Lysholm theo phân loại BMI

\begin{tabular}{|c|c|c|c|c|}
\hline & $\begin{array}{c}\text { Số khớp } \\
\mathbf{N = 3 2}\end{array}$ & $\begin{array}{c}\text { Điếm Lysholm } \\
\text { trước mổ }\end{array}$ & $\begin{array}{c}\text { Điểm Lysholm } \\
\text { sau mổ }\end{array}$ & \multirow{2}{*}{ Giá trị p } \\
\hline Bình thường & 27 & $61,7 \pm 0,56$ & $91,3 \pm 0,66$ & \multirow{2}{*}{0,001} \\
\hline Thừa cân & 5 & $56,8 \pm 0,66$ & $86,6 \pm 0,6$ & \\
\hline
\end{tabular}

- Đặc điểm chẩn đoán hình ảnh: mức độ thoái hóa gối theo phân độ Kellgren và Lawrence.

sàng và thang điểm Lysholmgiữa các nhóm tuổi, mức độ thoái hóa khớp gối và BMI.

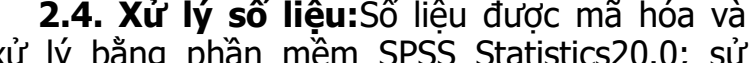

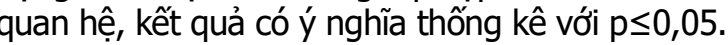

Giới: Nữ giới chiếm $84,4 \%$, nam giới chiếm . Tý lể nữ/nam là 5,4/1.

Tuổi: đô tuổi trung bình là 65 tuổi, phân bố BMI: BMI trung bình là 23,7, trong đó số hân thừa cần béo phì chiếm 15,6\% Bảng 1. Phân độ thoái hóa khớp gôi

\begin{tabular}{|c|c|c|}
\hline & Số khớp & Tỷ lệ (\%) \\
\hline Độ II & 6 & 18,8 \\
\hline Độ III & 26 & 81,2 \\
\hline Tống & 36 & 100 \\
\hline
\end{tabular}
ấn Thoái hóa khớp gôi độ III găp độ IV. Trong đó thoái hóa ngăn trong chiếm đến $88,9 \%$.

2.3. Kết quả phẫu thuật. Thời gian theo dôi trung bình sau phẫu thuật là $27,2 \pm 7,1$ tháng, gân nhất là 24 tháng, xa nhất là 40 tháng: Không có tai biến biên chứng nào đáng kể. Có 2 trường hợp nhiếm khuẩn nông vết mổ ngay sau phẫu thuật đều được điều trị mà không để lại di chứng nào. dụng kiểm định T-Test ghép căp để khảo sát mối

\section{1. Đăc điểm dich tễ}

3.2. Đăcc điểm chẩn đoán hình ảnh 
Nhận xét: Đa phần BN tham gia nghiên cứu có cân nặng bình thường, có sự khác biệt về thay đổi điểm Lysholm giữa nhóm $B N$ thừa cân và cân nặng bình thường $(p=0,001)$.

\section{BÀN LUÂ̂N}

1. Đặc điểm dịch tễ. Trong 32 bênh nhânthoái hóa khớp gối được phẫu thuật có 5 bệnh nhân nam và 27 bênh nhân nữ, độ tuổi trung bình là 65 (49-84). Kết quả nghiên cứu của chúng tôi tương đồng với Marcovigi $A$ và cộng sự1. Điều này cũng phù hợp với đặc điểm của THKG liên quan đến sự thay đổi nội tiết tố nữ ở tuổi tiền mãn kinh ${ }^{3}$.

Tỷ lệ bệnh nhân thừa cân trong nghiên cứu của chúng tôi là $15,6 \%$, BMI trung bình là $23,7 \pm$ 1,4 , trong đó thấp nhất là 19,9 cao nhất là 26 . Kết quả này cũng tương đương với báo cáo của Dretakis $\mathrm{K}$, Igoumenou ${ }^{2}$ và các tác giả khác. Thừa cân, béo phì là yếu tố quan trọng gây ra thoái hóa khớp gối và cũng là yếu tố quan trọng nhất thúc đẩy sự tiến triển của THKG ${ }^{6}$.

2. Đặc điểm chẩn đoán hình ảnh. Tất cả bệnh nhân trong nghiên cứu của chúng tôi đều thoái hóa khớp độ II hoặc độ III, không có trường hợp nào thoái hóa khớp gối độ IV, là do khi thoái hóa khớp độ IV trục chi đã biến đổi nghiên trọng, kèm theo thoái hóa 2 ngăn trong và ngoài hoăc cả 3 ngăn khớp gối dẫn đến không còn chỉ định thay khớp gối bán phần có hỗ trợ của Robot. Chúng tôi nhận thây dấu hiệu bệnh lý của thoái hóa khớp gối xuất hiện nhiều ở khớp đùi - chày trong (chiếm $88,9 \%$ ), phù hợp với đặc điểm cơ sinh học của khớp gối là ngắn trong chịu trọng lực nhiêu hơn ngăn ngoài và phù hợp với tỷ lệ phân bố cao của nhóm bệnh nhân có biến dạng gối vẹo trong.

3. Kết quả phẫu thuật. Qua nghiên cứu của chúng tôi thấy rằng có sự cải thiện về điểm Lysholm trước và sau mổ 60,9 $\pm 3,27 \rightarrow 90,6 \pm$ $3,64(p=0,000)$. Kết quả này là khá cao và cũng tương đương với một số nghiên cứu của Krych AJ $(2017)^{7}$ và Ji-HyeonYim $(2021)^{8}$. Có được kết quả này là do sự lựa chọn bệnh nhân trước mổ, chuẩn bị mổ tốt, kinh nghiệm của phẫu thuật viên, cùng hệ thống Robot giúp giảm thiểu các sai số trong phẫu thuật, đo đac và khảo sát các thông số giải phẫu trước mổ cẩn thận, cắt xương chính xác phối hợp với giải phóng phần mềm hợp lý, giảm đau sau mổ phối hợp với PHCN tốt cho kết quả sau phẫu thuâtt rất khả quan. Ngoài ra nhóm bệnh nhân được thay khớp gối bán phần đều không thoái hóa khớp gối đến độ IV, độ cuối cùng với chỉ định thay khớp gối toàn phần, do đó các chức năng khớp gối cũng không quá tồi ngay từ trước phẫu thuật.

Không có sự khác biệt về thay đổi điểm Lyshome sau phẫu thuật giữa các nhóm tuổi. Như vậy mặc dù có sư khác nhau về nhu cầu vận động ở các lứa tuổi, nhưng kết quả sớm về chức năng khớp gối không có sự khác biệt. Kết quả của chúng tôi cũng phù hợp với kết quả của các tác giả khác với theo dõi dài hơn trong 10 năm cũng không thấy sự khác biệt về cả chức năng và tỷ lệ thay lại của nhóm tuổi khác nhau được thay khớp gối bán phần không xi măng ${ }^{9}$.

Có sự khác biệt về điểm Lysholm giữa nhóm bệnh nhân có cân nặng bình thường và nhóm thừa cân $(p=0,000)$, cũng như giữa nhóm thoái hóa khớp gối độ II và độ III $(p=0,001)$. Kết quả của chúng tôi cũng phù hợp với kết quả nghiên cứu của nhiều tác giả khác khi cho rằng béo phì là yếu tố quan trọng nhất cho sự tiến triển của thoái hóa khớp gối. Cũng theo các tác giả này nếu trọng lượng cơ thể tăng lên $5 \mathrm{~kg}$ thì nguy cơ mắc bệnh tăng lên $35 \%$; mức độ thoái hóa gối cao hơn sẽ làm biến dạng khớp gối nhiều hơn so vơi mức độ thoái hóa thấp hơn cũng từ đo việc phẫu thuật kết quả cũng hạn chế hơn ${ }^{6}$.Một số tác giả khác thì cho rằng béo phì là nguyên nhân dẫn đến tỷ lệ thay lại khớp sau thay khớp gối bán phần cao và khuyến cáo khớp gối bán phần có lẽ không phù hợp để thay cho những người quá béo phì.

\section{KẾT LUÂN}

Thay khớp gối bán phần có hỗ trợ của Robot cho kết quả chức năng khớp gối của bệnh nhân cải thiện rất cao. Sử dụng Robot vào quá trình tính toán xử lí số liệu góp phần cải thiện tính chính xác của phẫu thuât thay khớp gối bán phần, cũng như góp phẩn cải thiện các triêu chứng của bệnh nhân trên lâm sàng. Do đó, việc ứng dụng phẫu thuật thay khớp gối bán phần có hỗ trợ của Robot nên được phát triển rộng rãi, để trở thành một kỹ thuật thường quy trong phẫu thuật thay khớp gối.

\section{TÀI LIÊU THAM KHẢO}

1. Marcovigi A, Zambianchi F, Sandoni D, Rivi E, Catani F. Robotic-arm assisted partial knee arthroplasty: a single centre experience. Acta BioMedica Atenei Parm. 2017;88(2S):54-59. doi:10.23750/abm.v88i2 -S.6514

2. Dretakis K, Igoumenou VG. Outcomes of roboticarm-assisted medial unicompartmental knee arthroplasty: minimum 3-year follow-up. Eur J Orthop Surg Traumatol Orthop Traumatol. 2019;29(6):13051311. doi:10.1007/s00590-019-02424-4

3. Mahajan A, Patni R. Menopause and Osteoarthritis: Any Association? J -Life Health. 
2018;9(4):171-172. doi:10.4103/jmh.JMH 15718

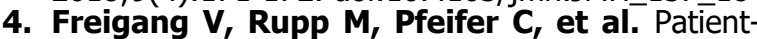
reported outcome after patient-specific unicondylar knee arthroplasty for unicompartmental knee osteoarthritis. BMC Musculoskelet Disord. 2020;21(1):1-9. doi:10.1186/s12891-020-03776-3

5. Pearle AD, van der List JP, Lee $L$, Coon TM, Borus TA, Roche MW. Survivorship and patient satisfaction of robotic-assisted medial unicompartmental knee arthroplasty at a minimum two-year follow-up. The Knee. 2017;24(2):419428. doi:10.1016/j.knee.2016.12.001

6. Hart D.J., Spector T. D. (2012). Change in body mass index during middle age affects risk of total knee arthoplasty due to osteoarthritis: A 19-year prospective study of 1003 women. The Knee; 19, 316-319.

7. Krych AJ, Reardon P, Sousa P, Pareek A,
Stuart M, Pagnano M. Unicompartmental Knee Arthroplasty Provides Higher Activity and Durability Than Valgus-Producing Proximal Tibial Osteotomy at 5 to 7 Years. J Bone Joint Surg Am. 2017;99(2):113-122. doi:10.2106/JBJS.15.01031

8. Comparison of High Tibial Osteotomy and Unicompartmental Knee Arthroplasty at a Minimum Follow-Up of 3 Years - ScienceDirect. Accessed September 22, 2021. https:// www.sciencedirect.com/ science/ article/abs/pii/S0883540312003622

9. Hasan Raza Mohammad, Stephen Mellon, Andrew Judge, Christopher Dodd David Murray (2021). The efect of age on the outcomes of cementless mobile bearing unicompartmental knee replacements. Knee Surgery, Sports Traumatology, Arthroscopy https://doi.org/ 10.1007/s00167-020-06428-0

\section{THỰC TRANG VÀ MỨC Độ THAM GIA DİCH VUU CHĂM SÓC SỨC KHỎE TẠI NHÀ Có KẾT NỐI Y TẾ TỪ XA CỦA NGƯờI DẨN THÀNH PHỐ ĐÀ NẪNG}

\section{TÓM TẮT}

Múc tiêu: Mô tả thực trang sử dụng dịch vụ chăm sóc sức khỏe tại nhà và tìm hiểu mức độ tham gia một số dịch vư y tế có kết nối y tế từ xa của người dấn thành phố Đà Nẵng. Phương pháp nghiên cứu: Nghiên cứu mô tả cắt ngang, được thực hiện trong tháng 03 năm 2021 trên 201 người dần đang sinh sống tại thành phố Đà Nẵng. Kết quả: Có $18,4 \%$ người đã từng sử dụng dịch vụ chăm sóc sức khỏe tại nhà. Trong số 15 dịch vụ sức khoẻ được hỏi thì mức độ rất muốn tham gia của người dân dao động từ $5,5 \%$ đến $41,3 \%$ và số người dân muốn tham gia là từ $56,7 \%$ đến $82,6 \%$. Về mức độ săn sàng tham gia của gia đình, có từ $17,9 \%$ đến $65,7 \%$ hộ gia đình sẽ tham gia các dịch vụ này khi có nhu cầu. Kết luận: Đa số người dân chưa từng sử dụng dịch vụ chăm sóc sức khoẻ tại nhà và phần đông người dân và hộ gia đình của họ sẵn sàng tham gia các dịch vụ này trong thời gian tới.

Tư khoá: chăm sóc sức khoẻ tại nhà, y tế từ xa, mức độ sẵn sàng.

\section{SUMMARY \\ THE SITUATION AND WILLINGNESS TO \\ PARTICIPATE IN HOME-CARE SERVICES WITH TELEMEDICINE OF THE RESIDENTS IN DA NANG CITY}

\footnotetext{
${ }^{1}$ Trường Đai họ Kỹ thuật $Y$ - Dược Đà Nã̃ng

${ }^{2}$ Viện Y tế công cộng và Y học dự phòng, Trường Đại học Y Hà Nôii

3Trường Đại hoc Y - Dước, Đai hoc Huê.

Chịu trách nhiệm chính: Võ Vắn Thắng

Email: vovanthang147@huemed-univ.edu.vn

Ngày nhận bài: 19.8.2021

Ngày phản biên khoa hoc: 15.10 .2021

Ngày duyệt bài: 25.10.2021
} home-care services and obtain the willingness to participate in home-care services with telemedicine of people in Da Nang city. Methods: A cross-sectional study was conducted on 201 people residing in Da Nang city in March 2021. Results: There was $18.4 \%$ of people who have ever used home-care services. Among the 15 health services questioned, the proportion of people who were tremendously willing to participate ranges from $5.5 \%$ to $41.3 \%$. The number of people who were pretty willing to participate was from $56.7 \%$ to $82.6 \%$. Regarding the level of family's willingness to participate, between $17.9 \%$ and $65.7 \%$ of households would participate in these services when needed. Conclusions: The study has shown that most people have never used home health care services and most people and their families are willing to participate in these services soon.

Keywords: home-care services, telemedicine, willingness.

\section{I. ĐẶT VẤN ĐỀ}

Đại dịch COVID-19 như là một chất xúc tác để chuyển đổi số và y tế từ xa (telemedicine) được chứng minh là một giải pháp thích hợp cho việc giảm thiểu nguy cơ lây truyền COVID-19 bắng cách ngăn chặn bất kỳ hình thức tiếp xúc vật lý trực tiếp nào, cung cấp dịch vụ chăm sóc liển tục cho cộng đồng và cuối cùng là giảm tỷ lệ mắc bệnh và tử vong khi bùng phát dịch [1]. Qua đó, người dân cộng đồng và người cung cấp dịch vụ cảm thây được hỗ trợ thuận lợi cho việc phát hiện, chẩn đoán và phòng ngừa sớm, đồng thời nó cũng giúp giảm tải áp lực cho các bênh viện.

Trước đây, các mô hình chăm CSSK chỉ có thể triển khai ngay tại bệnh viện thì giờ đây đã có thể được kết nối ngay tại nhà. Tuy nhiên, Việt 